\title{
Cold spray deposition of thermoplastic powder for road marking
}

\author{
Tatyana Brusentseva ${ }^{1, *}$,Vladislav Shikalov ${ }^{1}$, and Vasiliy Fomin ${ }^{1}$ \\ ${ }^{1}$ Khristianovich Institute of Theoretical and Applied Mechanics SB RAS, 630090 Novosibirsk, Russia
}

\begin{abstract}
The work is devoted to the deposition of polymer powder materials by cold spray method. Preliminary experimental results show that although an increase in the working air temperature leads to a noticeable increase in the deposition efficiency of thermoplastic (up to 0.05), it still remains low for cold spray. In the future, the proposed method for applying road marking will allow to obtain a coating with high wear resistance, increased service life, which can be used in various climatic zones in the temperature range from $-40{ }^{\circ} \mathrm{C}$ to $+40{ }^{\circ} \mathrm{C}$, which will allow replacing water and solvent based paints with least service life.
\end{abstract}

\section{Introduction}

Horizontal marking of the roadway is one of the most important technical means of organizing traffic, ensuring its safety. The main reasons for the marking destruction are the severe weather conditions, the use of aggressive anti-icing agents, the effects of fuels and lubricants, the poor condition of the roadway, and also a fairly frequent violation of the technology for making marking materials.

On federal highways, horizontal marking is applied using a variety of materials: highly filled paints and enamels, thermoplastics, polymer tapes [1 - 4]. Currently, most often road markings are applied with AK-511 paint (GOST R 52575-2006). It's believed that the service life of road marking paints doesn't exceed one year, and thermoplastics doesn't exceed two years. The advantage of thermoplastic materials over paints is that the applied layer thickness can be increased to $15-40 \mathrm{~mm}$, which allows to extend the life of the road marking. Currently, there is a problem of increasing the life of thermoplastic marking materials. The compositions of the marking thermoplastics based on petroleum resins are described in patent No. 1324553 (England), No. 420135 (Austria), and in patent No. 4713404 (USA) a composition based on epoxy resin is claimed. The most widespread for regions with severe climatic conditions are marking materials based on polyester resins hot-deposition thermoplastics [5].

Various technologies are used to apply thermoplastics, including airless paint, extruder, and spray. Today it is possible to spray powder paint by electrostatic spraying, painting with a flame, air flow spraying and tribostatic spraying [6]. The latest innovation in this area can be considered the technology of horizontal structured road marking. It is

\footnotetext{
* Corresponding author: brusentseva@itam.nsc.ru
} 
distinguished by increased abrasion resistance of the marking elements and their excellent adhesion to the wheel, as well as the presence of glass beads that give the marking the ability to retroreflect and improve its visibility [7]. One of the ways to reduce road traffic accidents is to use a noise strip of continuous longitudinal marking [8]. In addition, a road marking model has been developed, which is a layer of white, retroreflective and solidifying material poured into prefabricated recesses in an asphalt concrete pavement, while a flat surface is formed on the pavement [9].

Patented is a method of coating deposition from powder paints by plasma spraying [10]. In this way, the powder is applied by plasma spraying by feeding it into a high-temperature gas stream at a distance of 50-150 $\mathrm{mm}$ from the plasma torch nozzle and at an angle of inclination of the nozzle to the plasma stream $0-60^{\circ}$, using air or an air mixture as a plasma-forming gas and up to $10 \%$ hydrocarbon gases, and the polymerization is carried out simultaneously with spraying.

Cold spray method developed at the ITAM SB RAS [11] makes it possible to obtain coatings from metals, alloys, metal mixtures with ceramics and polymers while maintaining the structural and phase composition, including at the nanoscale. The essence of the method lies in the fact that the microparticles of the powder material are accelerated by the gas flow to supersonic speeds and, when they impact with the substrate, form a coating without melting. Currently, cold spray has several advantages over the well-known gas-thermal methods, namely:

- lack of thermal effects on particles and substrate;

- obtaining composite coatings while preserving the properties inherent in the original powder material, including at the nanoscale;

- $\quad$ ease of implementation, the absence of energy-intensive nodes, a high resource of components of the installation;

- the ability to collect and reuse powders, environmental friendliness.

\section{Materials and methods}

As a sprayed material, a thermoplastic composition «WAY»(GOST 52575-2006) was used. The composition includes a film-forming substance (15-30\%), a plasticizer $(3-10 \%)$, titanium dioxide $(4-10 \%)$, an anti-sedimentation additive $(3-10 \%)$, glass beads $(0-30 \%)$ and a mineral filler. A solid polyester resin containing up to $55 \%$ terephthalic acid and plasticized with one or more substances was used as a film-forming binder. As a substrate material, we used a roadbed with an asphalt concrete coating.

Spraying experiments were carried out at the cold spray facility (ITAM SB RAS) (Fig. 1), which includes a working gas heater, a drum-type powder feeder, and a prechamber-nozzle unit. The equipment makes it possible to maintain the necessary experimental parameters (air stagnation pressure and temperature) with high accuracy ( $1 \mathrm{~K}$ in temperature and $0.01 \mathrm{MPa}$ in pressure). As the positioning system, an industrial 6-axis robot KR16-2 (KUKA, Germany) was used, which makes it possible to position $(0.01 \mathrm{~mm})$ and move the nozzle $(1 \mathrm{~mm} / \mathrm{s})$ with high accuracy relative to the substrate. 


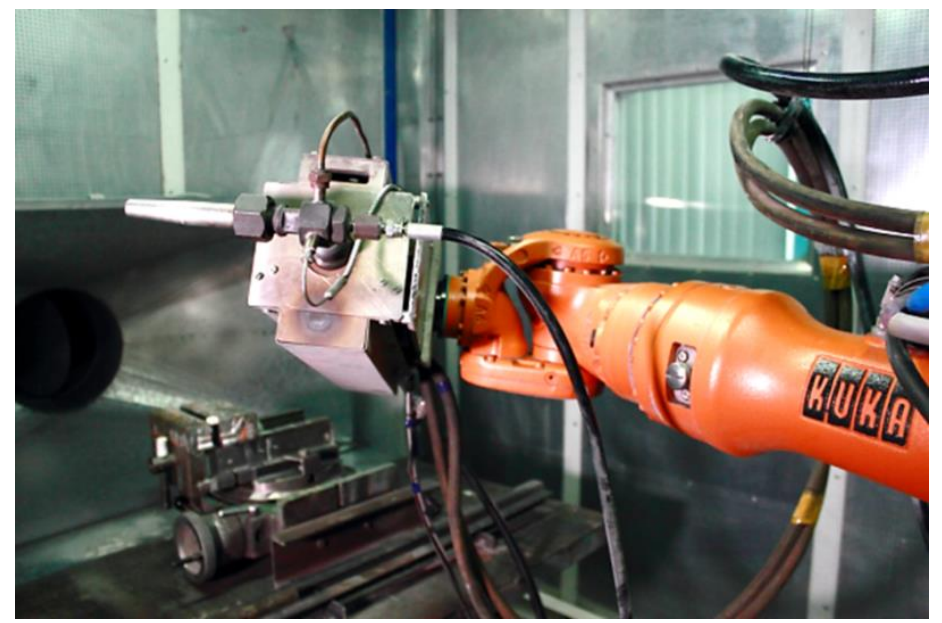

Fig. 1. Cold spray unit on industrial robot.

Spraying was carried out using an ejector nozzle of constant cross section with a diameter of $15 \mathrm{~mm}$ and a length of $140 \mathrm{~mm}$, a scheme of which is shown in Fig. 2.

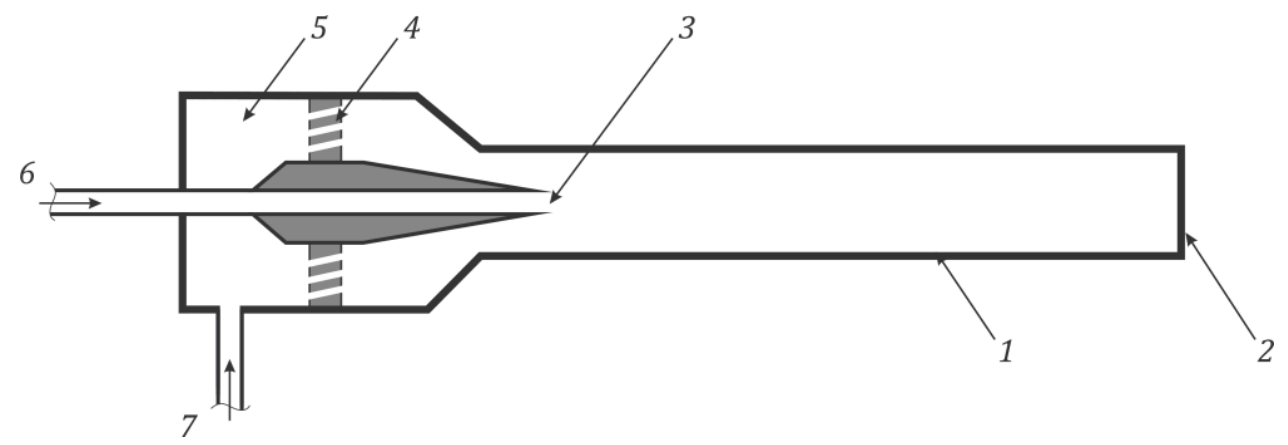

Fig. 2. Scheme of the ejector nozzle used in cold spray: 1 - nozzle, 2 - exit section, 3 -input particles, 4 - honeycomb, 5 - prechamber, 6 - powder feed, 7 - gas feed spray unit on industrial robot.

The use of an ejector nozzle makes it possible to use an open-type feeder operating at atmospheric pressure for powder feeding a spraying unit. As a result, the system for feeding powder is greatly simplified, and feeding of low-flowing materials and suspensions is also improved. One of the main features of the gas flow in the ejector nozzle is the presence of ejecting and ejected flows mixture. The flow of ejected air ensures the transportation of powder material from the feeder to the nozzle.

Air was chosen as the working gas, the pressure in the prechamber was kept constant and equal to $0.5 \mathrm{MPa}$, the temperature in the prechamber was chosen equal to $300 \mathrm{~K}$ and $433 \mathrm{~K}$. Standoff distance was constant and equal to $30 \mathrm{~mm}$, the nozzle traverse speed was $2 \mathrm{~mm} / \mathrm{s}$.

Deposition efficiency was determined as the ratio of the coating mass to the mass of the consumed powder. The sample was weighed before and after spraying; a portion of the powder, which was poured into the feeder, was also weighed.

Figure 3 shows photographs of the sample after deposition of thermoplastic using the ejector nozzle at a working air temperature of $300 \mathrm{~K}$ and $433 \mathrm{~K}$. 


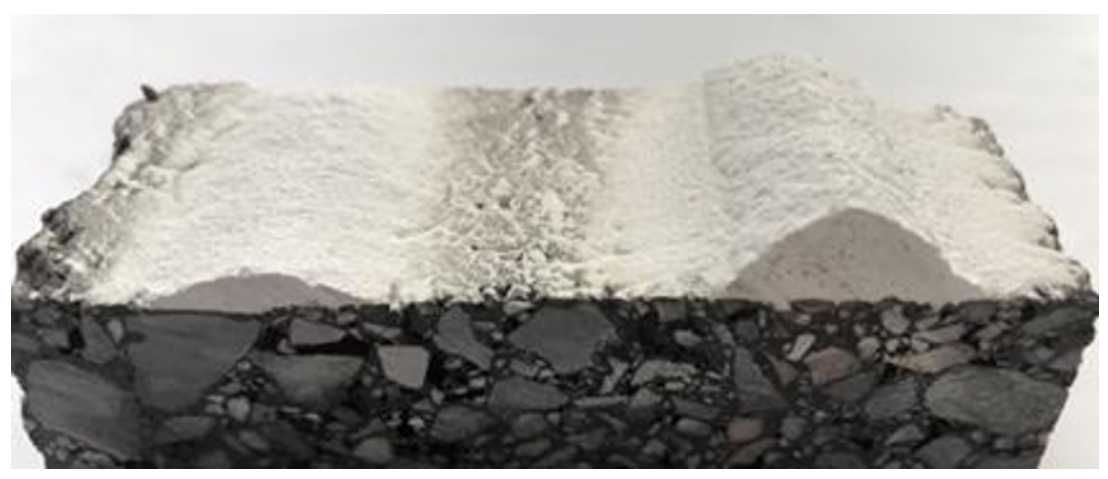

Fig. 3. Sprayed tracks on the surface of asphalt concrete, obtained at temperatures of working air of $300 \mathrm{~K}$ (left) and $433 \mathrm{~K}$ (right).

The measured values of the deposition efficiency are shown in Fig. 4.

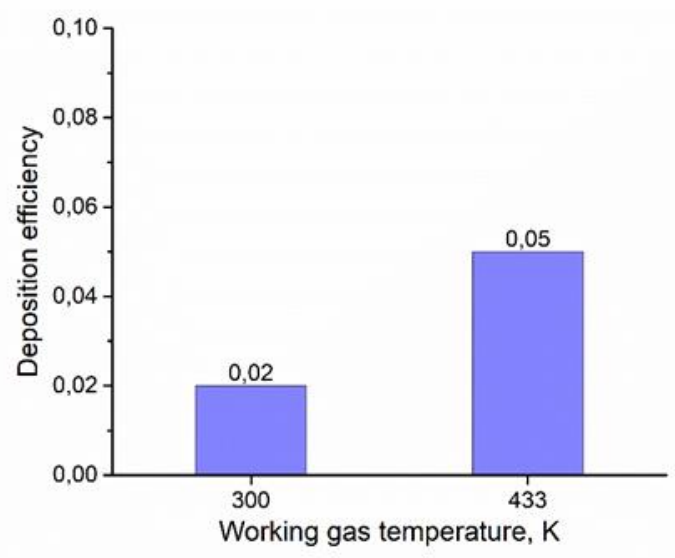

Fig. 4. The deposition efficiency of thermoplastic at different stagnation temperatures of the working gas.

Figure 4 shows that the process of thermoplastics deposition is accompanied by a very low deposition efficiency, the typical values of which for most cold sprayed metals are in the range 0.5-0.9. An increase in the temperature of the working air from $300 \mathrm{~K}$ to $433 \mathrm{~K}$, all other things being equal, makes it possible to increase the deposition efficiency of thermoplastic from 0.02 to 0.05 . The height of the spray tracks was $\sim 4 \mathrm{~mm}$ and $\sim 9 \mathrm{~mm}$ for spraying temperatures of $300 \mathrm{~K}$ and $433 \mathrm{~K}$, respectively.

\section{Conclusion}

A method for the thermoplastic deposition and its polymerization by the cold spray method is proposed. The experiments showed that the process of thermoplastics deposition by the cold spray method is accompanied by a low deposition efficiency. To increase the efficiency of spraying, additional optimization work is required related to the choice of nozzle geometry, spraying parameters, powder mixture composition, etc. The use of the cold spray method for applying thermoplastic to the roadway in the future will allow to increase the service life of the coating, which is associated with a noticeable thickening of the marking material layer. In addition, this type of marking is less time-consuming due to 
the fully mechanized process, which will replace the AK-511 white enamel, which is currently used, with modern, durable materials with improved technical properties.

The research was carried out within the framework of the Program of Fundamental Scientific Research of the state academies of sciences in 2013-2020 (projects No. AAAA-A17-1170306101349 and No. AAAA-A19-119051590004-5) using the equipment of the Joint Access Center «Mechanics» of ITAM SB RAS.

\section{References}

1. V.I. Bochkarev, Theoretical aspects of retroreflective road marking, 383-B00, 11 (2000)

2. MERCALIN PREFAB prefabricated thermoplastic elements for road marking, Information bulletin of the company "LKF VEJMARKERING A / S"(1996)

3. Road marking and retroreflective materials. Information Bulletin of Megotex LLC, 16 (2000)

4. V.D. Belov, The main provisions of the guidelines for marking roads, Roads of Russia of the XXI century, 2, 55-60 (2005)

5. A.P. Platonov, Synthetic materials used in building and repairing of car roads, Information Review 2, 31 (NIITEKHIM, Moscow, 1994)

6. K.G. Pugin, V.S. Yushkov. Modern materials for applying road marking, Materials of the international scientific and practical conference "Problems of the functioning of transport systems", 275 - 278, (2010)

7. Marking of roads with application of noise strip, Technical sciences - from theory to practice: collection (Novosibirsk, 2012)

8. B.S. Yushkov, A.M. Burgonutdinov, V.S. Yushkov, Modern approaches to the application of horizontal road marking, Bulletin of the Perm State Technical University "Environmental Protection, Transport, Life Safety", 1, 136 - 141 (2011)

9. L.Yu. Stupishin, A.O. Gladyshkin, M.S. Razumov, N.E. Bykovskaya, Patent No. 122661 of the Russian Federation (10 December 2001)

10. I.B. Minin, A.M. Anischenko, V.I. Pushin, A.V. Novoselov and Yu.V. Pasynkov, Patent No. 2213156 of the Russian Federation (5 February 2001)

11. A. Papyrin, V. Kosarev, S. Klinkov, A. Alkhimov, V. Fomin, Cold Spray Technology, Elsevier Science, 336 (2007) 